Review Article

\title{
Diagnosing Celiac Disease: Towards Wide-Scale Screening and Serology-Based Criteria?
}

\author{
Alina Popp, ${ }^{1,2}$ Laura Kivelä ${ }^{(D},{ }^{1,3}$ Valma Fuchs, ${ }^{4}$ and Kalle Kurppa ${ }^{1,5}$ \\ ${ }^{1}$ Center for Child Health Research, Tampere University and Department of Paediatrics, Tampere University Hospital, \\ Tampere, Finland \\ ${ }^{2}$ Institute for Mother and Child Health Bucharest, University of Medicine and Pharmacy "Carol Davila", Bucharest, Romania \\ ${ }^{3}$ University of Helsinki and Helsinki University Hospital, Children's Hospital and Pediatric Research Center, Helsinki, Finland \\ ${ }^{4}$ Celiac Disease Research Center, Tampere University, Tampere, Finland \\ ${ }^{5}$ The University Consortium of Seinäjoki, Seinäjoki, Finland
}

Correspondence should be addressed to Laura Kivelä; laura.kivela@fimnet.fi

Received 18 May 2019; Accepted 16 July 2019; Published 6 August 2019

Academic Editor: Walter Fries

Copyright (c) 2019 Alina Popp et al. This is an open access article distributed under the Creative Commons Attribution License, which permits unrestricted use, distribution, and reproduction in any medium, provided the original work is properly cited.

\begin{abstract}
Celiac disease is one of the most common food-related chronic disorders in children. Unfortunately, this multifaceted disease is challenging to recognize and remains markedly underdiagnosed. Screening of either known at-risk groups or even the whole population could increase the suboptimal diagnostic yield substantially. Many recent guidelines recommend screening of at least selected risk groups, but more wide-scale screening remains controversial. The increasing prevalence of celiac disease and the development of autoantibody assays have also led to a gradual shift in the diagnostics towards less invasive serology-based criteria in a subgroup of symptomatic children. The main open questions concern whether these criteria are applicable to all countries and clinical settings, as well as to adult patients. On the other hand, widening screening and the mistaken practice of initiating a gluten-free diet before the appropriate exclusion of celiac disease increase the number of borderline seropositive cases, which may also challenge the classical histopathological diagnostics. Sophisticated diagnostic methods and a deeper understanding of the natural history of early developing celiac disease may prove useful in these circumstances.
\end{abstract}

\section{Introduction}

With a prevalence of up to $1-3 \%$, celiac disease is one of the most common chronic gastrointestinal diseases [1-3]. It is evident that the diagnostics of such a frequent condition should be effective and practical. Unfortunately, the heterogeneous clinical presentation makes the disease difficult to recognize, and currently the great majority of affected individuals remain undiagnosed, leaving them vulnerable to long-term complications $[3,4]$. The most effective means of improving the diagnostic yield would be to screen known at-risk groups or even the whole population. The development of advanced serological tests has made screening rather straightforward, but the overall benefits of this approach remain a matter of debate [5]. Particularly controversial issues are the treatment of asymptomatic screen-detected individuals, the optimal age for rescreening, the optimal rescreening frequency, and the utilization of genetic testing to further delineate the susceptible cohort.

Traditionally, the diagnosis of celiac disease has been based on the demonstration of mucosal injury in duodenal biopsy. This invasive approach has been considered necessary to ensure the diagnosis before starting a demanding gluten-free diet. However, the high specificity of modern serological tests and the desire to reduce the need for invasive investigations led to the release of new criteria by the European Society for Paediatric Gastroenterology, Hepatology, and Nutrition (ESPGHAN) in 2012, which allow for the first time a noninvasive approach to diagnosis in a subgroup of children [6]. Although a huge leap forward, these guidelines paradoxically created new challenges, as they are currently not accepted in all countries and were not drawn 
TABLE 1: True prevalence of celiac disease based on screening studies and the proportion of clinically unrecognized patients.

\begin{tabular}{|c|c|c|c|c|}
\hline Reference and year & Country & Diagnostic criteria & Prevalence (\%) & Unrecognized (\%) \\
\hline \multicolumn{5}{|l|}{ Children } \\
\hline Mäki et al., 2003 [122] & Finland & Biopsy & 1.1 & 75.9 \\
\hline Tommasini et al., 2004 [123] & Italy & Biopsy & 1.1 & 94.5 \\
\hline Myléus et al., 2009 [2] & Sweden & Biopsy & 2.9 & 69.3 \\
\hline Mustalahti et al., 2010 [124] & UK & Seropositivity ${ }^{\mathrm{a}}$ or biopsy & 0.9 & 94.4 \\
\hline Laass et al., 2015 [125] & Germany & Seropositivity ${ }^{\mathrm{a}}$ & 0.8 & 91.7 \\
\hline \multicolumn{5}{|l|}{ Adults } \\
\hline West et al., 2003 [126] & UK & Seropositivity ${ }^{\mathrm{a}}$ & 1.2 & 95.7 \\
\hline Lohi et al., 2007 [1] & Finland & Seropositivity $^{\mathrm{a}}$ & 2.0 & 74.9 \\
\hline Mustalahti et al., 2010 [124] & Germany & Seropositivity ${ }^{\mathrm{a}}$ or biopsy & 0.3 & 93.3 \\
\hline Mustalahti et al., 2010 [124] & Italy & Seropositivity $^{\mathrm{a}}$ or biopsy & 0.7 & 97.1 \\
\hline Rubio-Tapia et al., 2012 [127] & USA & Seropositivity ${ }^{\mathrm{a}}$ & 0.7 & 90.1 \\
\hline Fukunaga et al., 2018 [128] & Japan & Biopsy & 0.1 & 100 \\
\hline
\end{tabular}

${ }^{a}$ Positive tissue transglutaminase and/or endomysial antibodies.

up for adults [7, 8]. Furthermore, even if the novel approach was adopted more widely, biopsy would still be needed in individuals with low positive serology, which are often diagnostically the most problematic cases. In fact, the number of such individuals is likely increasing due to more active screening.

In this review, we provide an overview of the current concepts of the diagnostics of celiac disease in children and adults. The main topics discussed are the possibilities for improving the suboptimal diagnostic yield and efforts to provide more unified diagnostic guidelines in the light of the most recent scientific evidence. Furthermore, we discuss the future directions in diagnostics, particularly concerning early developing celiac disease with minor or no histopathological changes and otherwise challenging cases.

\section{Diagnostic Approach: From Case Finding towards Screening}

The phenotype of celiac disease extends from varying gastrointestinal and extraintestinal complaints to an apparent lack of symptoms [9]. This variation makes recognition of the disease challenging, and currently the majority of affected children and adults remain undiagnosed (Table 1). The main approaches to detect untreated celiac disease are active case finding based on clinical symptoms and signs and targeted screening of at-risk groups, such as the relatives of celiac disease patients and subjects with certain other autoimmune diseases. However, there are major differences in the diagnostic approach between and even within countries, and this is also reflected in the inconsistencies between the true population-based prevalence of celiac disease and the number of actually diagnosed patients (Table 1).

2.1. Case Finding. Case finding is, in theory, an effective approach to find at least those patients with a characteristic clinical presentation. However, only those who seek medical help because of their symptoms or other clinical signs can be found, which requires activity from the patients themselves.
Furthermore, medical practitioners should be alert to the possibility of celiac disease behind the various complaints they encounter in daily practice. Unfortunately, this seems to be very challenging in the case of celiac disease. It has been observed that up to $85 \%$ of patients eventually found by screening have suffered from unrecognized symptoms for some time-even for several years-before the diagnosis [10-14]. The situation is further complicated by the low predictive value of even "typical" gastrointestinal symptoms for celiac disease $[15,16]$.

2.2. Screening: Current Approaches and Open Questions. There is a clear need for more effective diagnostic approaches rather than relying on ineffective case finding. The development of practical serological tests in recent decades has enabled easier noninvasive screening, but the matter of who should be screened is all but clear [5, 17]. Celiac disease fulfills most of the World Health Organization's general criteria for screening, but further studies are needed, particularly regarding the cost-effectiveness of screening and the natural history of clinically unrecognized patients [17]. The main issue is whether the benefits of an early diagnosis overcome the costs, laboriousness, and social burden of a gluten-free diet [5].

One argument against screening is the low risk for complications in unrecognized celiac disease patients. However, as already mentioned, many screening-detected subjects actually suffer from unrecognized symptoms. Moreover, even truly asymptomatic patients might be at risk for ill-health and long-term complications if left untreated [14, 18-22]. Particularly in children, many complications-such as dental enamel defects, poor height gain, and reduced bone accrual-may remain permanent if not detected early enough [23-25]. Furthermore, if the disease remains untreated until adulthood, there is an increased risk, e.g., for infertility, refractory celiac disease, and even small-bowel lymphoma $[26,27]$. Delayed diagnosis may also predispose to reduced quality of life, the incremental use of medicines, and persistent symptoms even on a gluten-free diet $[28,29]$. 
TABLE 2: Recommendations on screening for celiac disease according to the most recent diagnostic guidelines.

\begin{tabular}{|c|c|c|c|}
\hline Reference & Organization & Age group & Screening recommendation \\
\hline Downey et al., 2015 [66] & NICE & Children and adults & T1D, autoimmune thyroidal disease, and family risk \\
\hline Ludvigsson et al., 2014 [8] & BSG & Adults & T1D, irritable bowel syndrome, Down syndrome, and family risk \\
\hline Rubio-Tapia et al., 2013 [69] & ACG & Children and adults & Symptomatic T1D and family risk \\
\hline Husby et al., 2012 [6] & ESPGHAN & Children & $\begin{array}{l}\text { T1D, autoimmune thyroidal and liver diseases, IgA deficiency, } \\
\text { family risk, and Down, Turner, and Williams syndromes }\end{array}$ \\
\hline Hill et al., 2005 [7] & NASPGHAN & Children & $\begin{array}{l}\text { T1D, autoimmune thyroidal and liver diseases, family risk, } \\
\text { and Down, Turner, and Williams syndromes }\end{array}$ \\
\hline
\end{tabular}

ACG: American College of Gastroenterology; BSG: British Society of Gastroenterology; ESPGHAN: European Society for Paediatric Gastroenterology, Hepatology, and Nutrition; NASPGHAN: North American Society for Pediatric Gastroenterology, Hepatology, and Nutrition; NICE: The National Institute for Health and Care Excellence; T1D: type 1 diabetes.

A critical aspect regarding the rationale of screening is the patient's willingness to adhere to a life-long treatment. There has been concern that asymptomatic patients in particular would have poor motivation to maintain the diet with no apparent clinical benefits. Reported dietary adherence in screen-detected patients has varied from $23 \%$ to $93 \%[12,14,30-36]$. In more recent studies, the general tendency has been better adherence, possibly reflecting the increasing knowledge and better availability of gluten-free products in grocery stores and restaurants [31,37-41]. In fact, nowadays even asymptomatic screen-detected patients may show excellent dietary adherence [14, 42].

The most recent guidelines recommend screening for celiac disease in selected at-risk individuals (Table 2), although the actual implementation of the screening in clinical practice varies [43]. However, even with targeted screening, a substantial percentage of affected individuals will remain unrecognized [44]. The only option to find almost all celiac disease patients would be to screen the entire population or, alternatively, subjects with a genetic predisposition. This approach would still leave the question of the frequency of repeated screening after negative results, as celiac disease may develop at any age $[2,45]$. Furthermore, wide-scale screening would likely reveal a significant number of seropositive subjects who do not fulfill the current diagnostic criteria. At present, the prognosis and benefits of the early diagnosis and treatment of such cases are poorly known [46-51].

\section{Changing Guidelines and Development of Diagnostic Tools}

3.1. Histology and Serological Tests. During the past 70 years, the diagnostics of celiac disease has evolved from symptombased deduction to the use of sophisticated serological and histological methods. The development of biopsy techniques, followed by the description of duodenal injury, have been critical milestones [52, 53]. Before the 1970s, histology was the only diagnostic method in all age groups [54]. A less invasive approach for case finding could be attained by using serum antibodies, the first of which were antigliadin antibodies with moderate sensitivity and specificity $[55,56]$. More specific autoantibodies to reticulin and-particularly from the 1980s-endomysial antibodies (EmA) proved to be valuable tools for initial screening [57-59]. The identification of transglutaminase 2 as the autoantigen recognized by EmA [60] enabled practical ELISA tests for the detection of transglutaminase 2 antibodies (TG2ab) [61].

There have also been improvements in the histopathological assessment. The original biopsy capsule was gradually replaced by endoscopic duodenal sampling. In 1992, Marsh introduced the now widely used grouped classification for histological injury [62], and a modified version of this grading was later advocated by Oberhuber [63]. For these classifications, the histological injury is divided for practical purposes into three classes: infiltrative (Marsh 1), hyperplastic (Marsh 2), and atrophic (Marsh 3) lesions. In the Oberhuber classification, stage 3 is further divided into subclasses $3 \mathrm{a}, 3 \mathrm{~b}$, and $3 \mathrm{c}$. The more quantitative assessment of the mucosal damage using villous-height crypt depth measurement was introduced in the early 1980s and later further improved $[64,65]$. At present, however, this methodology is used mostly in research settings.

3.2. Evolving Guidelines towards a Less Invasive Diagnostic Approach. With some modifications, the ESPGHAN 1990 criteria for celiac disease remained the basis of practically all pediatric and adult diagnostic guidelines until 2012 [6-8, 66-70]. Demonstration of the characteristic histological lesion, followed by the resolution of symptoms on a glutenfree diet, allowed the establishment of the diagnosis, with positive serology giving further support to the diagnosis [67]. In the early $2000 \mathrm{~s}$, the testing of TG2ab came to the forefront in initial case screenings in both children and adults, although histological confirmation was still required $[7,71]$. Groups at risk for celiac disease were also increasingly recognized, and their low-threshold screening was recommended.

In 2012, the new EPSGHAN diagnostic criteria were launched [6]. The main driving forces for the revision were the necessity for general anesthesia for invasive endoscopy in children and the excellent positive predictive value of modern serological tests, particularly high tTGab values (Table 3) and positive EmA. For the first time, the revolutionary guidelines allowed diagnosis without biopsy in specific circumstances; i.e., for symptomatic children with tTGab values $>10 \times$ the upper limit of normal (ULN), positive EmA, and the presence of the at-risk human leucocyte antigen (HLA) DQ2/DQ8 haplotype [6]. Recent prospective studies have provided strong support for the accuracy of 
TABLE 3: Studies assessing the positive predictive value (PPV) of high tissue transglutaminase antibody (tTGab) values in the diagnosis of celiac disease.

\begin{tabular}{|c|c|c|c|c|c|}
\hline Reference & Cohort & Country & tTGab threshold & Number of tested assays & PPV (\%) \\
\hline \multicolumn{6}{|l|}{ Children } \\
\hline Paul et al., 2018 [76] & 157 & UK & 10x ULN & $1^{\mathrm{b}}$ & 100 \\
\hline Werkstetter et al., 2017 [72] & 707 & Multicenter & 10x ULN & 8 & $99.6-100^{\mathrm{C}}$ \\
\hline Wolf et al., 2017 [73] & 898 & Germany & 10x ULN & 1 & 98.8 \\
\hline Smarrazzo et al., 2017 [129] & 1,974 & Multicenter & 10x ULN & 8 & 96.1 \\
\hline Elitsur et al., 2017 [88] & 240 & USA & 10x ULN & $1^{\mathrm{b}}$ & 87.7 \\
\hline Trovato et al., 2015 [75] & 286 & Italy & 10x ULN & 1 & $91.0-92.5$ \\
\hline Gidrewicz et al., 2015 [130] & 17,505 & Canada & 10x ULN & 1 & 92.8 \\
\hline \multicolumn{6}{|l|}{ Adults } \\
\hline Efthymakis et al., 2017 [93] & 234 & Italy & 10x ULN & 2 & 97.6 \\
\hline Ganji et al., 2016 [131] & $299^{\mathrm{a}}$ & Iran & 10x ULN & 1 & 100 \\
\hline Tortora et al., 2014 [101] & 310 & Italy & 8.9x ULN & 1 & 100 \\
\hline
\end{tabular}

${ }^{a}$ Adults and adolescents. ${ }^{b}$ tTGab assay was not specified. ${ }^{c}$ Lowest obtained specificity when testing different diagnostic scenarios and excluding inconclusive patients. ULN: upper limit of normal; ND: no data.

these criteria [72, 73]. There is growing evidence that the nonbiopsy diagnostic approach could be applied reliably also for asymptomatic children [74-76] and without mandatory genetic testing [72]. In adults, histological evaluation has remained the cornerstone of the diagnosis, excluding the recently published Finnish guidelines that allow a nonbiopsy approach in some patients, regardless of their age [68].

\section{Challenges with the Diagnostic Criteria and Future Directions}

4.1. Technical Challenges. A major challenge in the current diagnostics is the lack of standardization in tTGab kits. This is particularly problematic for the nonbiopsy criteria, as the resulting incomparability between the assays may even predispose to misinterpretations $[77,78]$. In order to err on the side of safety, ESPGHAN recommends using only tTGab tests with an appropriate calibration curve [6]. Furthermore, the rather high ULN cutoff value and the requirement of HLA and EmA testing were included partly to control the assay variation. As mentioned, it might be possible to omit HLA testing in the future [72], and the role of EmA could also be questioned. Although EmA is highly specific, the required immunofluorescence method is laborious and not universally available. By applying well-validated tTGab assays, it might be possible to abandon EmA and also lower the diagnostic ULN threshold [72, 79].

Histopathology might not be as good a diagnostic reference standard as previously thought. The mucosal lesion can be patchy, the quality of the biopsies is often inadequate, and duodenal injury is not fully specific to celiac disease $[80,81]$. In order to improve the diagnostic yield, the current recommendation is to take at least four biopsies from the distal duodenum and one from the bulb $[6,66$, $82,83]$. However, due to the lower specificity, the added value of the duodenal bulb biopsy is controversial, and caution is needed when a diagnosis of celiac disease is based solely on bulb samples [84]. In addition, even if representa- tive biopsies are obtained, their correct handling and orientation are often challenging and prone to mistakes [65]. Accordingly, several studies have shown poor intra- and interobserver agreement between pathologists when applying a grouped histological classification [85-87].

4.2. Lack of Unified Guidelines. One of the main challenges with the current diagnostic criteria is their age- and country-related variation $[6,8,69]$. Despite the aforementioned problems, duodenal histopathology as the gold standard used to be the unifying feature of all the guidelines [67]. This changed radically when the ESPGHAN criteria introduced the possibility of omitting endoscopy for some European children [6], while the biopsy remains mandatory, e.g., in the USA [7]. These discrepancies might be explained to some extent by the different health care systems [88]. In addition, most of the studies on this issue have been made in Europe and, for unclear reasons, studies from North America have reported the inferior accuracy of tTGab tests (Table 3). As it is unlikely that children differ significantly between the continents, and since joint guidelines exist for many other diseases $[89,90]$, unified criteria for celiac disease would seem reasonable.

Another issue is the acceptance of serology-based diagnoses of celiac disease in adults by physicians. Only one of the current guidelines makes a clear statement on this issue; it does not support the taking of routine duodenal biopsies to reconfirm the diagnosis in adults when the diagnosis has been set strictly according to the ESPGHAN criteria [91]. This issue is particularly important in the transitional period from childhood to adulthood, when some young patients and/or their physicians may question the initial diagnosis [92]. To avoid confusion and the unnecessary repetition of diagnostic procedures, general acceptance-or preferably unified adult and pediatric criteria-is important.

Recent studies have given evidence that the nonbiopsy criteria would apply also to adults [79, 93, 94], but many experts remain cautious $[95,96]$. One fear is the misuse of 
the criteria by general practitioners [96-98]. However, there is evidence that accurate diagnostics can be achieved by education and close collaboration with primary care [94, 99]. Another feared consequence of omitting endoscopies is missing a coexisting disease or complication, such as refractory celiac disease or malignancy $[93,96]$. In practice, however, this does not seem to be a major problem, although more evidence is called for $[79,93,100,101]$. In general, the new guidelines do not aim to ban biopsies, but rather to offer the option for diagnosis without endoscopy in definite cases [6]. Endoscopy would still be preferable if red flag symptoms such as bloody stools, dysphagia, or severe weight loss appear, or if there is incomplete clinical recovery $[6,79,101]$.

4.3. Challenging Diagnostic Scenarios. Despite the tendency towards less invasive approaches, duodenal biopsy will likely remain a part of celiac disease diagnostics for quite some time. The main problem with serology is that the specificity decreases with lower antibody values [72, 79]. Unfortunately, such patients are usually also histologically the most problematic cases, as they may present only with mild or patchy duodenal changes $[46,80]$. In these circumstances, it is important to confirm that all stages of duodenal sampling and histological analysis have been done correctly $[65,102]$. The more quantitative measurement of architectural changes, e.g., by applying validated duodenal histomorphometry, might also prove useful [65].

The widening use of screening can be expected to increase the number of patients detected with early stage celiac disease and morphologically normal villi $[46,49,103]$. There is evidence that seropositive individuals may suffer from symptoms and signs already at this point and benefit from a gluten-free diet $[46,49,50,104]$, indicating that the whole definition of celiac disease might require reevaluation. Nevertheless, many such individuals are asymptomatic and do not develop duodenal lesions even during a long-term follow-up [49, 105-107]. It is essential to learn more about the natural history of early developing celiac disease in order to discern cases that would truly benefit from early diagnosis [108].

Another challenge in the differential diagnosis of patients with borderline or negative serology is brought by the now common practice of initiating a gluten-free diet before appropriate diagnostic investigations $[109,110]$. It still might be possible to establish the diagnosis using sophisticated techniques, e.g., determination of smallbowel mucosal $\gamma \delta+$ intraepithelial lymphocytes and celiac disease-specific tTG-targeted IgA deposits [46, 111-114]. Genetic testing and recently introduced innovative methods, such as HLA-DQ-gluten tetramer-based assays, might further help to exclude or confirm the presence of celiac disease [115].

4.4. Prevention of Celiac Disease? In the future, it might even be possible to proceed a step further, as several ongoing prospective birth cohort studies are steadily providing a deeper understanding of the early development of celiac disease [116-120]. Increasing information about the disturbed balance of genetics and environmental factors in celiac disease might offer possibilities for the early detection of high-risk children, and perhaps even provide means for primary prevention $[116-119,121]$.

\section{Conclusions}

Owing to the high prevalence of celiac disease, even minor changes in the diagnostic approach may have substantial effects on health care and society. It is evident that the only effective way to improve the currently unsatisfactory diagnostic yield is more widespread screening. Such an approach could be expected to prevent ill-health and severe complications in the long run, but it must be backed up with high-quality scientific evidence. Effective implementation of intensified case finding and screening also requires close collaboration with primary care and general practitioners, who are responsible for the firstline diagnostics.

Simultaneously with the increasing prevalence, the diagnostic criteria of celiac disease are currently undergoing revolutionary changes. At present, the serology-based diagnosis is limited to a minority of patients-i.e., mainly to symptomatic European children. This may cause problems, e.g., in the acceptance of the diagnosis in different countries and after the transition from pediatric to adult care. Since there is no apparent biological reason for the age- and site-related differences in the criteria, it would be desirable for more unified evidence-based global guidelines for celiac disease to be formed.

Notwithstanding the increasing tendency towards noninvasive diagnostics, biopsy will likely play an important role also in the future, particularly in individuals with low and/or borderline positive serology. In fact, the number of these cases will likely increase significantly concurrently with the widening screening and earlier testing. Novel sophisticated diagnostic tools may offer better possibilities for differential diagnosis in these often challenging situations. Open questions and issues remain concerning the natural history of these often asymptomatic individuals, particularly whether they should be diagnosed and treated with a gluten-free diet.

\section{Abbreviations}

EmA: $\quad$ Endomysial antibodies

ESPGHAN: European Society for Paediatric Gastroenterology, Hepatology, and Nutrition

HLA: Human leucocyte antigen

TG2ab: Transglutaminase 2 antibodies

ULN: Upper limit of normal.

\section{Conflicts of Interest}

The authors declare that they have no conflicts of interest.

\section{Acknowledgments}

This study was supported by the Competitive State Research Financing of Tampere University Hospital and the 
Foundation for Paediatric Research, the Maire Rossi Foundation, the Maud Kuistila Foundation, the Mary and Georg Ehrnrooth Foundation, the Paolo Foundation, and the Emil Aaltonen Foundation.

\section{References}

[1] S. Lohi, K. Mustalahti, K. Kaukinen et al., "Increasing prevalence of coeliac disease over time," Alimentary Pharmacology \& Therapeutics, vol. 26, no. 9, pp. 1217-1225, 2007.

[2] A. Myléus, A. Ivarsson, C. Webb et al., "Celiac disease revealed in 3\% of Swedish 12-year-olds born during an epidemic," Journal of Pediatric Gastroenterology and Nutrition, vol. 49, no. 2, pp. 170-176, 2009.

[3] P. Singh, A. Arora, T. A. Strand et al., "Global prevalence of celiac disease: systematic review and meta-analysis," Clinical Gastroenterology and Hepatology, vol. 16, no. 6, pp. 823836.e2, 2018

[4] P. Laurikka, S. Nurminen, L. Kivelä, and K. Kurppa, "Extraintestinal manifestations of celiac disease: early detection for better long-term outcomes," Nutrients, vol. 10, no. 8, p. 1015, 2018.

[5] R. Chou, C. Bougatsos, I. Blazina, K. Mackey, S. Grusing, and S. Selph, "Screening for celiac disease: evidence report and systematic review for the US Preventive Services Task Force," Journal of the American Medical Association, vol. 317, no. 12, pp. 1258-1268, 2017.

[6] S. Husby, S. Koletzko, I. R. Korponay-Szabó et al., "European Society for Pediatric Gastroenterology, Hepatology, and Nutrition guidelines for the diagnosis of coeliac disease," Journal of Pediatric Gastroenterology and Nutrition, vol. 54, no. 1, pp. 136-160, 2012.

[7] I. D. Hill, M. H. Dirks, G. S. Liptak et al., "Guideline for the diagnosis and treatment of celiac disease in children: recommendations of the North American Society for Pediatric Gastroenterology, Hepatology and Nutrition," Journal of Pediatric Gastroenterology and Nutrition, vol. 40, no. 1, pp. 1-19, 2005.

[8] J. F. Ludvigsson, J. C. Bai, F. Biagi et al., "Diagnosis and management of adult coeliac disease: guidelines from the British Society of Gastroenterology," Gut, vol. 63, no. 8, pp. 1210-1228, 2014.

[9] L. Kivelä, K. Kaukinen, M.-L. Lähdeaho et al., "Presentation of celiac disease in Finnish children is no longer changing: a 50-year perspective," The Journal of Pediatrics, vol. 167, no. 5, pp. 1109-1115.e1, 2015.

[10] D. Hansen, B. Brock-Jacobsen, E. Lund et al., "Clinical benefit of a gluten-free diet in type 1 diabetic children with screening-detected celiac disease: a population-based screening study with 2 years' follow-up," Diabetes Care, vol. 29, no. 11, pp. 2452-2456, 2006.

[11] E. J. van Koppen, J. J. Schweizer, C. G. D. S. Csizmadia et al., "Long-term health and quality-of-life consequences of mass screening for childhood celiac disease: a 10-year follow-up study," Pediatrics, vol. 123, no. 4, pp. e582-e588, 2009.

[12] S. Kinos, K. Kurppa, A. Ukkola et al., "Burden of illness in screen-detected children with celiac disease and their families," Journal of Pediatric Gastroenterology and Nutrition, vol. 55, no. 4, pp. 412-416, 2012.

[13] M. Jansen, M. van Zelm, M. Groeneweg et al., "The identification of celiac disease in asymptomatic children: the Gener- ation R Study," Journal of Gastroenterology, vol. 53, no. 3, pp. 377-386, 2017.

[14] L. Kivelä, K. Kaukinen, H. Huhtala, M.-L. Lähdeaho, M. Mäki, and K. Kurppa, "At-risk screened children with celiac disease are comparable in disease severity and dietary adherence to those found because of clinical suspicion: a large cohort study," The Journal of Pediatrics, vol. 183, pp. 115121.e2, 2017.

[15] K. D. Katz, S. Rashtak, B. D. Lahr et al., "Screening for celiac disease in a North American population: sequential serology and gastrointestinal symptoms," The American Journal of Gastroenterology, vol. 106, no. 7, pp. 1333-1339, 2011.

[16] A. Rosén, O. Sandström, A. Carlsson et al., "Usefulness of symptoms to screen for celiac disease," Pediatrics, vol. 133, no. 2, pp. 211-218, 2014.

[17] J. F. Ludvigsson, T. R. Card, K. Kaukinen et al., "Screening for celiac disease in the general population and in high-risk groups," United European Gastroenterology Journal, vol. 3, no. 2, pp. 106-120, 2015.

[18] M. A. Verkasalo, O. T. Raitakari, J. Viikari, J. Marniemi, and E. Savilahti, "Undiagnosed silent coeliac disease: a risk for underachievement?," Scandinavian Journal of Gastroenterology, vol. 40, no. 12, pp. 1407-1412, 2005.

[19] I. R. Korponay-Szabó, K. Szabados, J. Pusztai et al., "Population screening for coeliac disease in primary care by district nurses using a rapid antibody test: diagnostic accuracy and feasibility study," BMJ, vol. 335, no. 7632, pp. 1244-1247, 2007.

[20] J. Turner, G. Pellerin, and D. Mager, "Prevalence of metabolic bone disease in children with celiac disease is independent of symptoms at diagnosis," Journal of Pediatric Gastroenterology and Nutrition, vol. 49, no. 5, pp. 589-593, 2009.

[21] S. Nurminen, L. Kivelä, J. Taavela et al., "Factors associated with growth disturbance at celiac disease diagnosis in children: a retrospective cohort study," BMC Gastroenterology, vol. 15, no. 1, p. 125, 2015.

[22] S. Björck, C. Brundin, M. Karlsson, and D. Agardh, "Reduced bone mineral density in children with screening-detected celiac disease," Journal of Pediatric Gastroenterology and Nutrition, vol. 65, no. 5, pp. 526-532, 2017.

[23] A. G. Kalayci, A. Kansu, N. Girgin, O. Kucuk, and G. Aras, "Bone mineral density and importance of a gluten-free diet in patients with celiac disease in childhood," Pediatrics, vol. 108, no. 5, article E89, 2001.

[24] B. Weiss, Y. Skourikhin, D. Modan-Moses, E. Broide, A. Fradkin, and Y. Bujanover, "Is adult height of patients with celiac disease influenced by delayed diagnosis," The American Journal of Gastroenterology, vol. 103, no. 7, pp. 1770-1774, 2008.

[25] J. Cheng, T. Malahias, P. Brar, M. T. Minaya, and P. H. R. Green, "The association between celiac disease, dental enamel defects, and aphthous ulcers in a United States cohort," Journal of Clinical Gastroenterology, vol. 44, no. 3, pp. 191-194, 2010.

[26] G. Bona, D. Marinello, and G. Oderda, "Mechanisms of abnormal puberty in coeliac disease," Hormone Research in Pcediatrics, vol. 57, no. 2, pp. 63-65, 2002.

[27] T. Ilus, K. Kaukinen, L. J. Virta, E. Pukkala, and P. Collin, "Incidence of malignancies in diagnosed celiac patients: a population-based estimate," The American Journal of Gastroenterology, vol. 109, no. 9, pp. 1471-1477, 2014. 
[28] P. Paarlahti, K. Kurppa, A. Ukkola et al., "Predictors of persistent symptoms and reduced quality of life in treated coeliac disease patients: a large cross-sectional study," BMC Gastroenterology, vol. 13, no. 1, p. 75, 2013.

[29] V. Fuchs, K. Kurppa, H. Huhtala, P. Collin, M. Mäki, and K. Kaukinen, "Factors associated with long diagnostic delay in celiac disease," Scandinavian Journal of Gastroenterology, vol. 49, no. 11, pp. 1304-1310, 2014.

[30] E. Fabiani, L. Taccari, I.-M. Rätsch, S. Di Giuseppe, G. Coppa, and C. Catassi, "Compliance with gluten-free diet in adolescents with screening-detected celiac disease: a 5-year follow-up study," The Journal of Pediatrics, vol. 136, no. 6, pp. 841-843, 2000.

[31] E. Roma, A. Roubani, E. Kolia, J. Panayiotou, A. Zellos, and V. P. Syriopoulou, "Dietary compliance and life style of children with coeliac disease," Journal of Human Nutrition and Dietetics, vol. 23, no. 2, pp. 176-182, 2010.

[32] A. Paavola, K. Kurppa, A. Ukkola et al., "Gastrointestinal symptoms and quality of life in screen-detected celiac disease," Digestive and Liver Disease, vol. 44, no. 10, pp. 814818, 2012.

[33] C. Webb, A. Myléus, F. Norström et al., "High adherence to a gluten-free diet in adolescents with screening-detected celiac disease," Journal of Pediatric Gastroenterology and Nutrition, vol. 60, no. 1, pp. 54-59, 2015.

[34] E. Altobelli, R. Paduano, T. Gentile et al., "Health-related quality of life in children and adolescents with celiac disease: survey of a population from Central Italy," Health and Quality of Life Outcomes, vol. 11, no. 1, p. 204, 2013.

[35] S. Mahadev, R. Gardner, S. K. Lewis, B. Lebwohl, and P. H. Green, "Quality of life in screen-detected celiac disease patients in the United States," Journal of Clinical Gastroenterology, vol. 50, no. 5, pp. 1-397, 2016.

[36] J. B. Torres, E. Román, M. Cilleruelo, M. Márquez, M. Mearin, and C. Fernández, "Health-related quality of life in Spanish children with coeliac disease," Journal of Pediatric Gastroenterology and Nutrition, vol. 62, no. 4, pp. 603-608, 2016.

[37] O. Jadrešin, Z. Mišak, K. Sanja, Z. Sonicki, and V. Žižić, "Compliance with gluten-free diet in children with coeliac disease," Journal of Pediatric Gastroenterology and Nutrition, vol. 47, no. 3, pp. 344-348, 2008.

[38] G. Wagner, G. Berger, U. Sinnreich et al., "Quality of life in adolescents with treated coeliac disease: influence of compliance and age at diagnosis," Journal of Pediatric Gastroenterology and Nutrition, vol. 47, no. 5, pp. 555-561, 2008.

[39] S. Errichiello, O. Esposito, R. Di Mase et al., "Celiac disease: predictors of compliance with a gluten-free diet in adolescents and young adults," Journal of Pediatric Gastroenterology and Nutrition, vol. 50, no. 1, pp. 54-60, 2010.

[40] K. Kurppa, O. Lauronen, P. Collin et al., "Factors associated with dietary adherence in celiac disease: a nationwide study," Digestion, vol. 86, no. 4, pp. 309-314, 2012.

[41] K. MacCulloch and M. Rashid, "Factors affecting adherence to a gluten-free diet in children with celiac disease," Paediatrics \& Child Health, vol. 19, no. 6, pp. 305-309, 2014.

[42] K. Kurppa, A. Paavola, P. Collin et al., "Benefits of a glutenfree diet for asymptomatic patients with serologic markers of celiac disease," Gastroenterology, vol. 147, no. 3, pp. 610617.e1, 2014.
[43] A. Pham-Short, K. C. Donaghue, G. Ambler, H. Phelan, S. Twigg, and M. E. Craig, "Screening for celiac disease in type 1 diabetes: a systematic review," Pediatrics, vol. 136, no. 1 , pp. e170-e176, 2015.

[44] C. Catassi and A. Fasano, "Coeliac disease. The debate on coeliac disease screening-are we there yet?," Nature Reviews Gastroenterology \& Hepatology, vol. 11, no. 8, pp. 457-458, 2014.

[45] A. Vilppula, K. Kaukinen, L. Luostarinen et al., "Increasing prevalence and high incidence of celiac disease in elderly people: a population-based study," BMC Gastroenterology, vol. 9, no. 1, article 49, 2009.

[46] K. Kurppa, P. Collin, M. Viljamaa et al., "Diagnosing mild enteropathy celiac disease: a randomized, controlled clinical study," Gastroenterology, vol. 136, no. 3, pp. 816-823, 2009.

[47] R. Auricchio, A. Tosco, E. Piccolo et al., "Potential celiac children: 9-year follow-up on a gluten-containing diet," American Journal of Gastroenterology, vol. 109, no. 6, pp. 913-921, 2014.

[48] S. L. Vriezinga, R. Auricchio, E. Bravi et al., "Randomized feeding intervention in infants at high risk for celiac disease," The New England Journal of Medicine, vol. 371, no. 14, pp. 1304-1315, 2014.

[49] U. Volta, G. Caio, F. Giancola et al., "Features and progression of potential celiac disease in adults," Clinical Gastroenterology and Hepatology, vol. 14, no. 5, pp. 686-693.e1, 2016.

[50] R. Mandile, V. Discepolo, S. Scapaticci et al., "The effect of gluten-free diet on clinical symptoms and the intestinal mucosa of patients with potential celiac disease," Journal of Pediatric Gastroenterology and Nutrition, vol. 66, no. 4, pp. 654-656, 2018.

[51] K. Kurppa, T. Räsänen, P. Collin et al., "Endomysial antibodies predict celiac disease irrespective of the titers or clinical presentation," World Journal of Gastroenterology, vol. 18, no. 20, pp. 2511-2516, 2012.

[52] M. Shiner, "Duodenal biopsy," The Lancet, vol. 267, no. 6906, pp. 17-19, 1956.

[53] J. Sakula and M. Shiner, "Coeliac disease with atrophy of the small-intestine mucosa," The Lancet, vol. 270, no. 7001, pp. 876-877, 1957.

[54] H. A. Weijers, B. Lindquist, C. H. M. Anderson et al., "Diagnostic criteria in coeliac disease," Acta Paediatrica Scandinavica, vol. 59, p. 461, 1970.

[55] U. Volta, G. R. Corazza, M. Frisoni et al., "IgA antigliadin antibodies and persistence of jejunal lesions in adult coeliac disease," Digestion, vol. 47, no. 2, pp. 111-114, 1990.

[56] M. Mäki, O. Hällstrom, and A. Marttinen, "Reaction of human non-collagenous polypeptides with coeliac disease autoantibodies," The Lancet, vol. 338, no. 8769, pp. 724-725, 1991.

[57] P. P. Seah, L. Fry, M. A. Rossiter, A. V. Hoffbrand, and E. J. Holborow, "Anti-reticulin antibodies in childhood coliac disease,” The Lancet, vol. 2, no. 7726, pp. 681-682, 1971.

[58] T. P. Chorzelski, E. H. Beutner, J. Sulej et al., "IgA antiendomysium antibody. A new immunological marker of dermatitis herpetiformis and coeliac disease," British Journal of Dermatology, vol. 111, no. 4, pp. 395-402, 1984.

[59] B. Ladinser, E. Rossipal, and K. Pittschieler, "Endomysium antibodies in coeliac disease: an improved method," Gut, vol. 35, no. 6, pp. 776-778, 1994.

[60] W. Dieterich, T. Ehnis, M. Bauer et al., "Identification of tissue transglutaminase as the autoantigen of celiac disease," Nature Medicine, vol. 3, no. 7, pp. 797-801, 1997. 
[61] S. Sulkanen, T. Halttunen, K. Laurila et al., "Tissue transglutaminase autoantibody enzyme-linked immunosorbent assay in detecting celiac disease," Gastroenterology, vol. 115, no. 6, pp. 1322-1328, 1998.

[62] M. N. Marsh, "Gluten, major histocompatibility complex, and the small intestine: a molecular and immunobiologic approach to the spectrum of gluten sensitivity ('celiac sprue')," Gastroenterology, vol. 102, no. 1, pp. 330-354, 1992.

[63] G. Oberhuber, G. Granditsch, and H. Vogelsang, "The histopathology of coeliac disease: time for a standardized report scheme for pathologists," European Journal of Gastroenterology \& Hepatology, vol. 11, no. 10, pp. 1185-1194, 1999.

[64] P. Kuitunen, I. Kosnai, and E. Savilahti, "Morphometric study of the jejunal mucosa in various childhood enteropathies with special reference to intraepithelial lymphocytes," Journal of Pediatric Gastroenterology and Nutrition, vol. 1, no. 4, pp. 525-532, 1982.

[65] J. Taavela, O. Koskinen, H. Huhtala et al., "Validation of morphometric analyses of small-intestinal biopsy readouts in celiac disease," PLoS One, vol. 8, no. 10, article e76163, 2013.

[66] L. Downey, R. Houten, S. Murch, and D. Longson, "Recognition, assessment, and management of coeliac disease: summary of updated NICE guidance," BMJ, vol. 351, no. article h4513, 2015.

[67] J. A. Walker-Smith, S. Guandalini, J. Schmitz, D. H. Shmerling, and J. K. Visakorpi, "Revised criteria for diagnosis of coeliac disease. Report of Working Group of European Society of Paediatric Gastroenterology and Nutrition," Archives of Disease in Childhood, vol. 65, no. 8, pp. 909911, 1990.

[68] Working group set up by the Finnish Medical Society Duodecim and the Finnish Gastroenterology Society, "Celiac disease. Current Care Guidelines, 2018," March 2019, http://www. kaypahoito.fi/web/kh/suositukset/suositus?id=hoi08001\#K1.

[69] A. Rubio-Tapia, I. D. Hill, C. P. Kelly, A. H. Calderwood, J. A. Murray, and American College of Gastroenterology, "ACG clinical guidelines: diagnosis and management of celiac disease," American Journal of Gastroenterology, vol. 108, no. 5, pp. 656-676, 2013.

[70] J. Bai and C. Ciacci, "World Gastroenterology Organisation global guidelines: celiac disease February 2017," Journal of Clinical Gastroenterology, vol. 51, no. 9, pp. 755-768, 2017.

[71] A. Rostom, J. A. Murray, and M. F. Kagnoff, "American Gastroenterological Association (AGA) Institute technical review on the diagnosis and management of celiac disease," Gastroenterology, vol. 131, no. 6, pp. 1981-2002, 2006.

[72] K. J. Werkstetter, I. R. Korponay-Szabó, A. Popp et al., “Accuracy in diagnosis of celiac disease without biopsies in clinical practice," Gastroenterology, vol. 153, no. 4, pp. 924-935, 2017.

[73] J. Wolf, D. Petroff, T. Richter et al., "Validation of antibodybased strategies for diagnosis of pediatric celiac disease without biopsy," Gastroenterology, vol. 153, no. 2, pp. 410419.e17, 2017.

[74] A. Popp, M. Mihu, M. Munteanu et al., "Prospective antibody case finding of coeliac disease in type 1 diabetes children: need of biopsy revisited," Acta Paediatrica, vol. 102, no. 3, pp. e102-e106, 2013.

[75] C. M. Trovato, M. Montuori, C. Anania et al., "Are ESPGHAN "biopsy-sparing” guidelines for celiac disease also suitable for asymptomatic patients?," The American Journal of Gastroenterology, vol. 110, no. 10, pp. 1485-1489, 2015.

[76] S. P. Paul, B. K. Sandhu, C. H. Spray, D. Basude, and P. Ramani, "Evidence supporting serology-based pathway for diagnosing celiac disease in asymptomatic children from high-risk groups," Journal of Pediatric Gastroenterology and Nutrition, vol. 66, no. 4, pp. 641-644, 2018.

[77] W. Egner, A. Shrimpton, R. Sargur, D. Patel, and K. Swallow, "ESPGHAN guidance on coeliac disease 2012: multiples of ULN for decision making do not harmonise assay performance across centres," Journal of Pediatric Gastroenterology and Nutrition, vol. 55, no. 6, pp. 733-735, 2012.

[78] L. Beltran, M. Koenig, W. Egner et al., "High-titre circulating tissue transglutaminase-2 antibodies predict small bowel villous atrophy, but decision cut-off limits must be locally validated," Clinical and Experimental Immunology, vol. 176, no. 2, pp. 190-198, 2014.

[79] V. Fuchs, K. Kurppa, H. Huhtala et al., "Serology-based criteria for adult coeliac disease have excellent accuracy across the range of pre-test probabilities," Alimentary Pharmacology \& Therapeutics, vol. 49, no. 3, pp. 277-284, 2019.

[80] A. Ravelli, V. Villanacci, C. Monfredini, S. Martinazzi, V. Grassi, and S. Manenti, "How patchy is patchy villous atrophy? Distribution pattern of histological lesions in the duodenum of children with celiac disease," American Journal of Gastroenterology, vol. 105, no. 9, pp. 2103-2110, 2010.

[81] L. Elli, F. Branchi, R. Sidhu et al., "Small bowel villous atrophy: celiac disease and beyond," Expert Review of Gastroenterology \& Hepatology, vol. 11, no. 2, pp. 125-138, 2017.

[82] I. D. Hill, "The role of biopsies in childhood celiac disease-do we need less or more?," Journal of Pediatric Gastroenterology and Nutrition, vol. 64, no. 2, pp. 173-174, 2017.

[83] S. Husby, J. A. Murray, and D. A. Katzka, "AGA clinical practice update on diagnosis and monitoring of celiac disease-changing utility of serology and histologic measures: expert review," Gastroenterology, vol. 156, no. 4, pp. 885889,2019

[84] J. Taavela, A. Popp, I. R. Korponay-Szabo et al., “A prospective study on the usefulness of duodenal bulb biopsies in celiac disease diagnosis in children: urging caution," American Journal of Gastroenterology, vol. 111, no. 1, pp. 124133, 2016.

[85] C. Arguelles-Grande, C. A. Tennyson, S. K. Lewis, P. H. R. Green, and G. Bhagat, "Variability in small bowel histopathology reporting between different pathology practice settings: impact on the diagnosis of coeliac disease," Journal of Clinical Pathology, vol. 65, no. 3, pp. 242-247, 2012.

[86] A. Picarelli, R. Borghini, G. Donato et al., "Weaknesses of histological analysis in celiac disease diagnosis: new possible scenarios," Scandinavian Journal of Gastroenterology, vol. 49, no. 11, pp. 1318-1324, 2014.

[87] C. Montén, K. Bjelkenkrantz, A. H. Gudjonsdottir et al., "Validity of histology for the diagnosis of paediatric coeliac disease: a Swedish multicentre study," Scandinavian Journal of Gastroenterology, vol. 51, no. 4, pp. 427-433, 2016.

[88] Y. Elitsur, T. Sigman, R. Watkins et al., "Tissue transglutaminase levels are not sufficient to diagnose celiac disease in North American practices without intestinal biopsies," Digestive Diseases and Sciences, vol. 62, no. 1, pp. 175-179, 2017.

[89] M. Jones, S. Koletzko, K. Goodman et al., "Joint ESPGHAN/NASPGHAN guidelines for the management of Helicobacter 
pylori in children and adolescents (update 2016)," Journal of Pediatric Gastroenterology and Nutrition, vol. 64, no. 6, pp. 991-1003, 2017.

[90] M. M. Tabbers, C. DiLorenzo, M. Y. Berger et al., "Evaluation and treatment of functional constipation in infants and children," Journal of Pediatric Gastroenterology and Nutrition, vol. 58, no. 2, pp. 265-281, 2014.

[91] J. F. Ludvigsson, L. Agreus, C. Ciacci et al., "Transition from childhood to adulthood in coeliac disease: the Prague consensus report," Gut, vol. 65, no. 8, pp. 1242-1251, 2016.

[92] C. O’Leary, P. Wieneke, M. Healy, C. Cronin, P. O’Regan, and F. Shanahan, "Celiac disease and the transition from childhood to adulthood: a 28-year follow-up," The American Journal of Gastroenterology, vol. 99, no. 12, pp. 2437-2441, 2004.

[93] K. Efthymakis, M. Serio, A. Milano et al., "Application of the biopsy-sparing ESPGHAN guidelines for celiac disease diagnosis in adults: a real-life study," Digestive Diseases and Sciences, vol. 62, no. 9, pp. 2433-2439, 2017.

[94] G. K. T. Holmes, J. M. Forsyth, S. Knowles, H. Seddon, P. G. Hill, and A. S. Austin, "Coeliac disease: further evidence that biopsy is not always necessary for diagnosis," European Journal of Gastroenterology \& Hepatology, vol. 29, no. 6, pp. 640-645, 2017.

[95] M. Kurien, J. F. Ludvigsson, D. S. Sanders, and authors of the BSG guidelines, "A no biopsy strategy for adult patients with suspected coeliac disease: making the world gluten-free," Gut, vol. 64, no. 6, pp. 1003-1004, 2015.

[96] L. J. Marks, M. Kurien, and D. S. Sanders, "The serological diagnosis of adult coeliac disease-a cautious step forward?," Gastroenterology and Hepatology From Bed to Bench, vol. 11, no. 3, pp. 175-177, 2018.

[97] F. Biagi, P. I. Bianchi, J. Campanella, G. Zanellati, and G. R. Corazza, "The impact of misdiagnosing celiac disease at a referral centre," Canadian Journal of Gastroenterology, vol. 23, no. 8, pp. 543-545, 2009.

[98] M. Jinga, A. Popp, D. V. Balaban, C. Jurcut, and C. Jurcut, "Physicians' attitude and perception regarding celiac disease: a questionnaire-based study," The Turkish Journal of Gastroenterology, vol. 29, no. 4, pp. 419-426, 2018.

[99] H. Hin, G. Bird, P. Fisher, N. Mahy, and D. Jewell, "Coeliac disease in primary care: case finding study," BMJ, vol. 318, no. 7177, pp. 164-167, 1999.

[100] M. Salo, P. Collin, S. Kyrönpalo, M. Rasmussen, H. Huhtala, and K. Kaukinen, "Age, symptoms and upper gastrointestinal malignancy in primary care endoscopy," Scandinavian Journal of Gastroenterology, vol. 43, no. 1, pp. 122-127, 2008.

[101] R. Tortora, N. Imperatore, P. Capone et al., "The presence of anti-endomysial antibodies and the level of anti-tissue transglutaminases can be used to diagnose adult coeliac disease without duodenal biopsy," Alimentary Pharmacology \& Therapeutics, vol. 40, no. 10, pp. 1223-1229, 2014.

[102] H. J. Freeman, "Pearls and pitfalls in the diagnosis of adult celiac disease," Canadian Journal of Gastroenterology, vol. 22, no. 3, pp. 273-280, 2008.

[103] K. Kurppa, M. Ashorn, S. Iltanen et al., "Celiac disease without villous atrophy in children: a prospective study," The Journal of Pediatrics, vol. 157, no. 3, pp. 373-380.e1, 2010.

[104] K. Kurppa, P. Collin, H. Sievänen, H. Huhtala, M. Mäki, and K. Kaukinen, "Gastrointestinal symptoms, quality of life and bone mineral density in mild enteropathic coeliac disease: a prospective clinical trial," Scandinavian Journal of Gastroenterology, vol. 45, no. 3, pp. 305-314, 2010.

[105] A. Tosco, V. M. Salvati, R. Auricchio et al., "Natural history of potential celiac disease in children," Clinical Gastroenterology and Hepatology, vol. 9, no. 4, pp. 320-325, 2011.

[106] E. Lionetti, S. Castellaneta, R. Francavilla et al., "Long-term outcome of potential celiac disease in genetically at-risk children: the prospective CELIPREV cohort study," Journal of Clinical Medicine, vol. 8, no. 2, p. 186, 2019.

[107] R. Auricchio, R. Mandile, M. R. Del Vecchio et al., "Progression of celiac disease in children with antibodies against tissue transglutaminase and normal duodenal architecture," Gastroenterology, vol. 157, no. 2, pp. 413-420.e3, 2019.

[108] M. Borrelli, C. Gianfrani, G. Lania et al., "In the intestinal mucosa of children with potential celiac disease IL-21 and IL-17A are less expressed than in the active disease," American Journal of Gastroenterology, vol. 111, no. 1, pp. 134144, 2016.

[109] A. Sapone, J. C. Bai, C. Ciacci et al., "Spectrum of glutenrelated disorders: consensus on new nomenclature and classification," BMC Medicine, vol. 10, no. 1, p. 13, 2012.

[110] B. Palmieri, M. Vadala', and C. Laurino, "A review of the gluten-free diet in non-celiac patients: beliefs, truths, advantages and disadvantages," Minerva Gastroenterologica e Dietologica, vol. 65, no. 2, 2018.

[111] I. R. Korponay-Szabó, T. Halttunen, Z. Szalai et al., "In vivo targeting of intestinal and extraintestinal transglutaminase 2 by coeliac autoantibodies," Gut, vol. 53, no. 5, pp. 641-648, 2004.

[112] T. T. Salmi, P. Collin, T. Reunala, M. Mäki, and K. Kaukinen, "Diagnostic methods beyond conventional histology in coeliac disease diagnosis," Digestive and Liver Disease, vol. 42, no. 1, pp. 28-32, 2010.

[113] O. Koskinen, P. Collin, I. Korponay-Szabo et al., "Glutendependent small bowel mucosal transglutaminase 2-specific IgA deposits in overt and mild enteropathy coeliac disease," Journal of Pediatric Gastroenterology and Nutrition, vol. 47, no. 5, pp. 436-442, 2008.

[114] M. Borrelli, M. Maglio, I. R. Korponay-Szabó et al., "Intestinal anti-transglutaminase 2 immunoglobulin A deposits in children at risk for coeliac disease (CD): data from the PreventCD study," Clinical and Experimental Immunology, vol. 191, no. 3, pp. 311-317, 2018.

[115] V. K. Sarna, K. E. A. Lundin, L. Mørkrid, S.-W. Qiao, L. M. Sollid, and A. Christophersen, "HLA-DQ-gluten tetramer blood test accurately identifies patients with and without celiac disease in absence of gluten consumption," Gastroenterology, vol. 154, no. 4, pp. 886-896.e6, 2018.

[116] E. Liu, H.-S. Lee, C. A. Aronsson et al., "Risk of pediatric celiac disease according to HLA haplotype and country," The New England Journal of Medicine, vol. 371, no. 1, pp. 42-49, 2014.

[117] C. A. Aronsson, H.-S. Lee, S. Koletzko et al., "Effects of gluten intake on risk of celiac disease: a case-control study on a Swedish birth cohort," Clinical Gastroenterology and Hepatology, vol. 14, no. 3, pp. 403-409.e3, 2016.

[118] M. Barroso, S. A. Beth, T. Voortman et al., "Dietary patterns after the weaning and lactation period are associated with celiac disease autoimmunity in children," Gastroenterology, vol. 154, no. 8, pp. 2087-2096.e7, 2018. 
[119] K. Størdal, R. A. White, and M. Eggesbø, "Early feeding and risk of celiac disease in a prospective birth cohort," Pediatrics, vol. 132, no. 5, pp. e1202-e1209, 2013.

[120] E. Liu, F. Dong, A. E. Barón et al., "High incidence of celiac disease in a long-term study of adolescents with susceptibility genotypes," Gastroenterology, vol. 152, no. 6, pp. 13291336.e1, 2017.

[121] C. Meijer, R. Shamir, H. Szajewska, and L. Mearin, "Celiac disease prevention," Frontiers in Pediatrics, vol. 6, p. 368, 2018.

[122] M. Mäki, K. Mustalahti, J. Kokkonen et al., "Prevalence of celiac disease among children in Finland," The New England Journal of Medicine, vol. 348, no. 25, pp. 2517-2524, 2003.

[123] A. Tommasini, T. Not, V. Kiren et al., "Mass screening for coeliac disease using antihuman transglutaminase antibody assay," Archives of Disease in Childhood, vol. 89, no. 6, pp. 512-515, 2004.

[124] K. Mustalahti, C. Catassi, A. Reunanen et al., "The prevalence of celiac disease in Europe: results of a centralized, international mass screening project," Annals of Medicine, vol. 42, no. 8 , pp. 587-595, 2010 .

[125] M. Laass, R. Schmitz, H. Uhlig, K. P. Zimmer, M. Thamm, and S. Koletzko, "The prevalence of celiac disease in children and adolescents in Germany," Deutsches Ärzteblatt International, vol. 112, no. 33-34, pp. 553-560, 2015.

[126] J. West, K. Fleming, L. J. Tata, T. R. Card, and C. J. Crooks, "Incidence and prevalence of celiac disease and dermatitis herpetiformis in the UK over two decades: populationbased study," American Journal of Gastroenterology, vol. 109, no. 5, pp. 757-768, 2014.

[127] A. Rubio-Tapia, J. Ludvigsson, T. Brantner, J. A. Murray, and J. E. Everhart, "The prevalence of celiac disease in the United States," The American Journal of Gastroenterology, vol. 107, no. 10, pp. 1538-1544, 2012.

[128] M. Fukunaga, N. Ishimura, C. Fukuyama et al., "Celiac disease in non-clinical populations of Japan," Journal of Gastroenterology, vol. 53, no. 2, pp. 208-214, 2018.

[129] A. Smarrazzo, G. Magazzù, M. Ben-Hariz et al., "Variability of anti-human transglutaminase testing in celiac disease across Mediterranean countries," World Journal of Gastroenterology, vol. 23, no. 24, pp. 4437-4443, 2017.

[130] D. Gidrewicz, K. Potter, C. L. Trevenen, M. Lyon, and D. J. Butzner, "Evaluation of the ESPGHAN celiac guidelines in a North American pediatric population," The American Journal of Gastroenterology, vol. 110, no. 5, pp. 760-767, 2015.

[131] A. Ganji, A. Esmaeilzadeh, A. Bahari et al., "Correlation between cut-off level of tissue transglutaminase antibody and Marsh classification," Middle East Journal of Digestive Diseases, vol. 8, no. 4, pp. 318-322, 2016. 


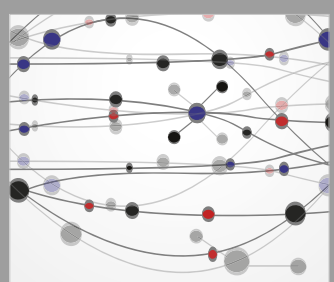

The Scientific World Journal
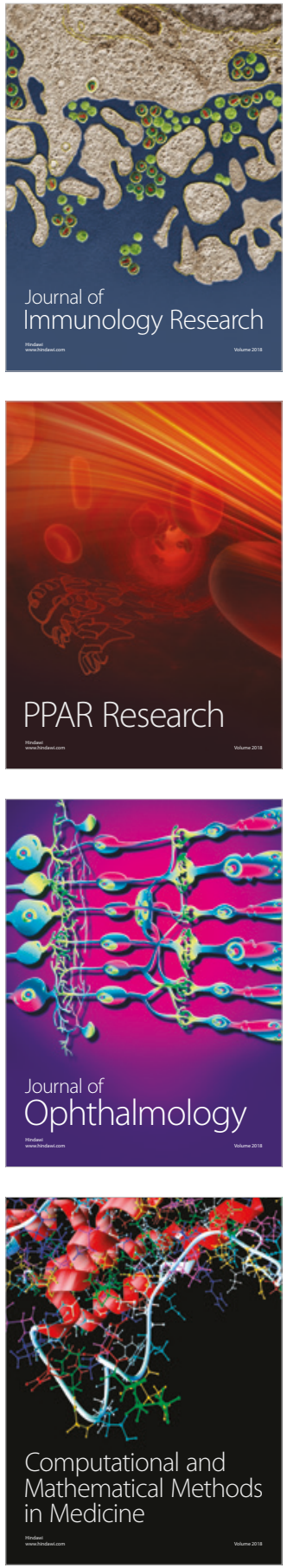

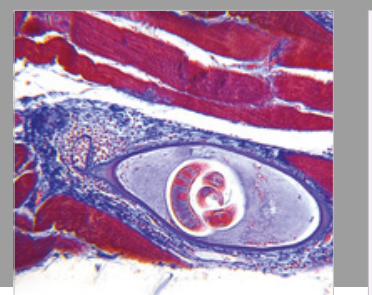

Gastroenterology Research and Practice

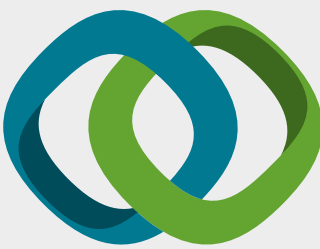

\section{Hindawi}

Submit your manuscripts at

www.hindawi.com
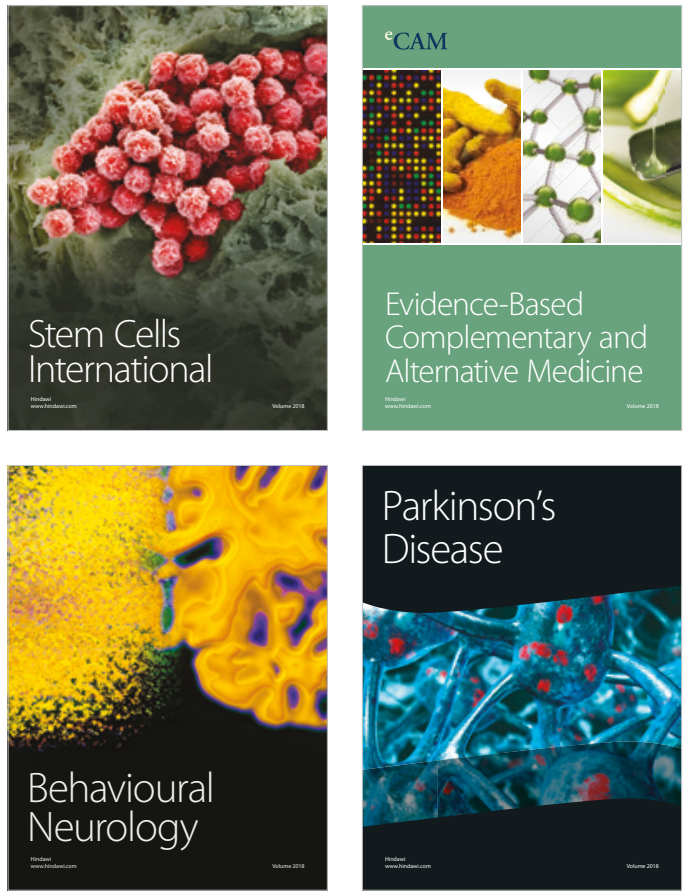

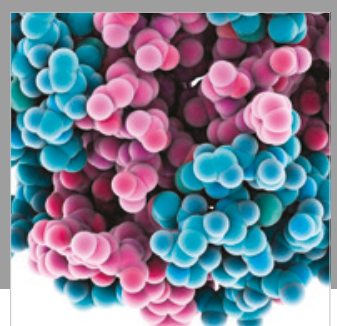

ournal of

Diabetes Research

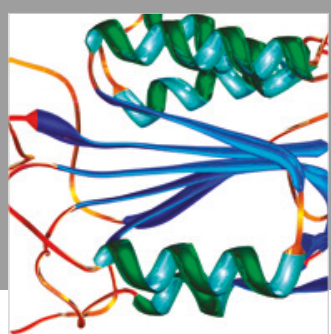

Disease Markers
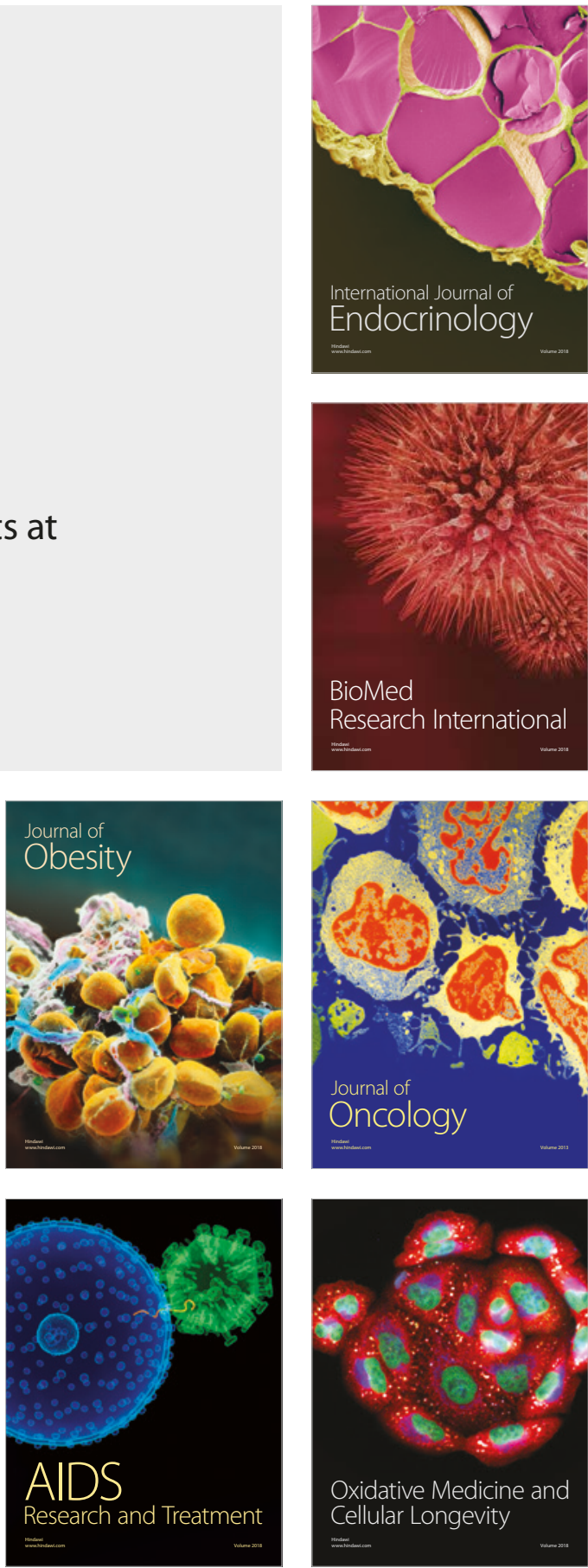